Cite this: Dalton Trans., 2014, 43, 3911

Received 6th November 2013, Accepted 3rd January 2014

DOI: $10.1039 / \mathrm{c} 3 \mathrm{dt} 53140 \mathrm{f}$

www.rsc.org/dalton

\section{Substitution versus redox reactions of gold(III) complexes with L-cysteine, L-methionine and glutathione $\uparrow$}

\author{
Mirjana D. Đurović, ${ }^{a}$ Živadin D. Bugarčić, ${ }^{\star^{a}}$ Frank W. Heinemann ${ }^{\mathrm{b}}$ and \\ Rudi van Eldik*b
}

The influence of tridentate, nitrogen donor ligands, on the stability of gold(II) complexes under physiological conditions was investigated. The interaction of $[\mathrm{Au}(\mathrm{terpy}) \mathrm{Cl}]^{2+}$ (terpy $=2,2^{\prime}: 6^{\prime} 2^{\prime \prime}$ terpyridine), $\left[\mathrm{Au}(\mathrm{bpma}) \mathrm{Cl}^{2+}\left(\mathrm{bpma}=\right.\right.$ bis(pyridyl-methyl)amine), $\left[\mathrm{Au}(\mathrm{dien}) \mathrm{Cl}^{2+}(\right.$ dien $=$ diethylenetriamine $)$ and $\left[\mathrm{AuCl}_{4}\right]^{-}$with the biologically relevant thiols, L-cysteine (L-Cys) and glutathione (GSH), and thioether, L-methionine (L-Met), was studied using UV-Vis spectroscopy, cyclic voltammetry, ${ }^{1} \mathrm{H}$ NMR spectroscopy and ESI-MS. In this study, the rate constants for substitution reactions between monofunctional gold(III) complexes and sulfur donor ligands in aqueous solution were determined at different initial concentrations of reactants, chloride ions, $\mathrm{pH}$ and constant ionic strength. The obtained second-order rate constants for the reaction with L-methionine in the absence of added chloride at $\mathrm{pH} 2.5$ and $25^{\circ} \mathrm{C}$ follow the sequence $(7.5 \pm 0.4) \times 10^{3}>(4.5 \pm 0.1) \times 10^{2}>88.3 \pm 0.8 \mathrm{M}^{-1} \mathrm{~s}^{-1}$ for the terpy, bpma and dien complexes, respectively, demonstrating that the substitution step could be detected prior to the reduction step. This behavior was expected due to the influence of a decreasing $\pi$-donor ability of the chelate ligands, which slows down the substitution reactions along the series of complexes studied. In order to throw more light on the mechanism of biological activity of gold(III) compounds, such a systematic study was performed for all the mentioned thiols and thioether.

\section{Introduction}

Undoubtedly, gold has been the hallmark of all times, from ancient times to the $21^{\text {st }}$ century. Its use started in 4000 years $\mathrm{BC}$ with the production of decorative fashion objects and developed through its monetary role to medical applications. Today, it is well known that $\mathrm{Au}(\mathrm{I})$ exhibits anti-arthritic, antirheumatic and antimicrobial activities. ${ }^{1-3}$ In contrast, the behavior of $\mathrm{Au}(\mathrm{III})$ is questionable. Although it is isoelectronic and isostructural with $\mathrm{Pt}(\mathrm{II}),{ }^{4}$ it can still not be applied as an anticancer drug because of its ability to oxidize numerous biologically relevant molecules. However, the oxidation of sulfur containing amino acids, such as L-Cys, L-Met and the tripeptide GSH, is a reversible process. ${ }^{5}$

\footnotetext{
${ }^{a}$ University of Kragujevac, Faculty of Science, R. Domanovića 12, 34000 Kragujevac, Serbia. E-mail: bugarcic@kg.ac.rs; Fax: +381(0)34335040; Tel: +381(0)34300262

${ }^{b}$ Inorganic Chemistry, Department of Chemistry and Pharmacy, University of

Erlangen-Nürnberg, Egerlandstrasse 1, 91058 Erlangen, Germany.

E-mail: vaneldik@chemie.uni-erlangen.de; Fax: +49(0)9131 8527387;

Tel: $+49(0) 91318527357$

$\dagger$ Electronic supplementary information (ESI) available. See DOI: $10.1039 / \mathrm{c} 3 \mathrm{dt} 53140 \mathrm{f}$
}

The thiol and thioether groups are part of amino acids and their oxidation by metal ions has been studied for decades because of their important role in both the structure and function of proteins. ${ }^{6}$ Oxidatively modified proteins accumulate during aging, oxidative stress and in age-related diseases, and some of them were found in liver, heart, skeletal muscle, kidney, and in regions of the brain. ${ }^{5}$ L-Cysteine, L-methionine and the tripeptide glutathione (GSH, $\gamma$-glu-cys-gly) contain at least three potential donor groups, viz. the free $\alpha$-amino group, the carboxylate group, and a single reducing group, thiol or thioether. Based on Pearson's theory ${ }^{7}$ and the softness of these groups, it is expected that the group containing a sulfur donor atom should show the highest affinity for $\mathrm{Au}(\mathrm{I})$ and $\mathrm{Au}(\mathrm{III})$ ions. Due to the fact that tests on their biological activity show positive and promising results, ${ }^{8-11}$ studies dealing with the elucidation of the underlying reaction mechanisms are still in progress.

The development of $\mathrm{Au}(\mathrm{III})$ complexes has been encouraged by the fact that an increase in the number of nitrogen donor atoms in the coordination sphere of $\mathrm{Au}(\mathrm{III})$ leads to a significant decrease in the reduction potential. Isab and coworkers have shown that $\left[\mathrm{Au}(\mathrm{CN})_{4}\right]^{-}$does not react with L-Met. ${ }^{12}$ It is apparent that the ability of gold to form stable complexes is of 
the greatest importance to improve their behavior under physiological conditions.

Motivated by the observation that Au(III) compounds show outstanding cytotoxic properties in different cancer lines, ${ }^{2,9}$ we have studied the reactions of a series of $\mathrm{Au}$ (III) complexes and a simple Au(III) salt. The chemical behavior of these compounds in aqueous solution was studied in detail, focusing in particular on their substitution behavior. Studies based on similar reactions date back to the mid-1970s, when it was suspected that substitution proceeds too fast to be detected, ${ }^{13-15}$ until in 1980 Elding and coworkers suggested that there is no substitution reaction at all. ${ }^{16}$ Here we report evidence for rapid substitution processes that occur prior to the redox reaction.

\section{Experimental}

\section{Chemicals}

All starting materials were used as received from commercial sources. Potassium tetrachloroaurate $\left(\mathrm{KAuCl}_{4}\right)$, diethylenetriamine (dien), di-(2-picolyl)amine (bpma), and 2,2':6',2"-terpyridine (terpy) used for the synthesis of the studied complexes were purchased from Aldrich. Reduced glutathione (GSH), L-methionine (L-Met) and L-cysteine (L-Cys) were purchased from Acros Organics, Sigma Aldrich and Fluka. Deuterated solvents employed in NMR measurements were obtained from Acros Organics. All other chemicals were of analytical reagent grade.

\section{Synthesis of the complexes}

The monofunctional $\mathrm{Au}(\mathrm{III})$ complexes used in this study, [Au(dien)Cl $] \mathrm{Cl}_{2},[\mathrm{Au}(\mathrm{bpma}) \mathrm{Cl}] \mathrm{Cl}_{2}$, and $[\mathrm{Au}($ terpy$) \mathrm{Cl}] \mathrm{Cl}_{2}$, were synthesized according to published procedures. ${ }^{17-19}$ Chemical analyses of the synthesized complexes: $[\mathrm{Au}(\operatorname{dien}) \mathrm{Cl}] \mathrm{Cl}_{2}$. Calc. for $\mathrm{C}_{4} \mathrm{H}_{13} \mathrm{AuCl}_{3} \mathrm{~N}_{3}$ : C, 11.82; $\mathrm{H}, 3.22 ; \mathrm{N}, 10.34$; found: $\mathrm{C}, 11.80$; $\mathrm{H}, 3.21 ; \mathrm{N}, 10.29$. [Au(bpma)Cl] $\mathrm{Cl}_{2}$. Calc. for $\mathrm{C}_{12} \mathrm{H}_{13} \mathrm{AuCl}_{3} \mathrm{~N}_{3}$ : C, 28.68; H, 2.61; N, 8.36; found: C, 28.64; H, 2.58; N, 8.34. $\left[\mathrm{Au}(\right.$ terpy)Cl$] \mathrm{Cl}_{2}$. Calc. for $\mathrm{C}_{15} \mathrm{H}_{11} \mathrm{AuCl}_{3} \mathrm{~N}_{3}, \mathrm{C}, 33.57 ; \mathrm{H}, 2.07 ; \mathrm{N}$, 7.83; found: C, 33.51; H, 2.01; N, 7.78.

\section{Solutions}

The kinetics of the ligand substitution reactions were studied in aqueous solution. A $0.1 \mathrm{M} \mathrm{NaClO}_{4}$ (Merck, p.a.) solution and a freshly prepared $25 \mathrm{mM}$ Hepes buffer (Acros Organics) were used for the measurements at $\mathrm{pH}$ 7. The $\mathrm{pH}$ value of the solution was adjusted with $\mathrm{HClO}_{4}$ and $\mathrm{HCl}-\mathrm{DCl}$ to 2.5, whereas $\mathrm{NaCl}$ was used to adjust the chloride concentration. For the UV-Vis monitored reactions, the concentration of the gold complexes was $1 \times 10^{-4} \mathrm{M}$, although higher concentrations $(1 \mathrm{mM})$ were used in the cyclic voltammetric and ${ }^{1} \mathrm{H}$ NMR studies. The nucleophile solutions were freshly prepared daily to prevent oxidation of the amino acids over time. Double distilled water was used throughout.

\section{Instrumentation}

Spectroscopic techniques. UV-Vis spectra were recorded on Cary 5G, Hewlett-Packard 8452A and Perkin Elmer Lambda 35 double-beam spectrophotometers equipped with thermostated cell holders and a $0.88 \mathrm{~cm}$ path length tandem cuvette. The $\mathrm{pH}$ of the aqueous solutions was carefully measured using a Mettler Delta $350 \mathrm{pH}$ meter previously calibrated with standard buffer solutions (Merck) at two $\mathrm{pH}$ values (4 and 7). Kinetic measurements on fast reactions were monitored using an Applied Photophysics SX.18 MV stopped-flow instrument coupled to an online data acquisition system. The temperature of the instrument was controlled to within $\pm 0.1{ }^{\circ} \mathrm{C}$. First-order rate constants, $k_{\mathrm{obsd}}$, were obtained directly from the stoppedflow software program.

Cyclic voltammetry. Cyclovoltammetric (CV) measurements were performed in a one-compartment three-electrode cell using a glassy carbon (GC) working electrode (Metrohm) with a disc diameter of $2 \mathrm{~mm}$, a saturated calomel reference electrode (SCE) (Fischer Scientific) and a platinum wire as a counter electrode (Metrohm). Measurements were recorded with an Autolab PGSTAT 30 unit at room temperature. The working electrode surface was polished with $0.05 \mu \mathrm{M}$ alumina (Buechler) on a microcloth with water as the lubricant. The test solution with a volume of $10 \mathrm{ml}$ was deoxygenated by passing a stream of high purity $\mathrm{N}_{2}$ through the solution for at least 15 min prior to the measurements, and an inert atmosphere of $\mathrm{N}_{2}$ was maintained over the solution during the measurements. All CVs were recorded with a scan rate of $0.1 \mathrm{~V} \mathrm{~s}^{-1}$ at $25{ }^{\circ} \mathrm{C}$, while the potential of the electrode was cycled between +1.5 and $-1.5 \mathrm{~V}$. The supporting electrolyte was a $0.4 \mathrm{M} \mathrm{NaCl}$ solution that contained $0.003 \mathrm{M} \mathrm{HCl}$ for the reaction performed at $\mathrm{pH}$ 2.5. All potentials are reported with respect to the saturated calomel electrode (SCE, $0.24 \mathrm{~V}$ vs. NHE).

${ }^{1} \mathbf{H}$ NMR. All ${ }^{1} \mathrm{H}$ NMR measurements were performed on a Varian Gemini 2000 spectrometer (200 MHz) using $5 \mathrm{~mm}$ NMR tubes. Sodium trimethylsilylpropane-3-sulfonate (TSP) was used as an internal reference. All NMR spectra were processed using the NMRnotebook and the chemical shifts are reported in parts per million ( $\mathrm{ppm})$. The $\mathrm{pH}$ was adjusted using an Iskra MA 5704 pH meter, which was calibrated with a Fischer-certified buffer solution of $\mathrm{pH} 4$.

Electrospray ionization-mass spectrometry. MS measurements were performed on a UHR-TOF Bruker Daltonik (Bremen, Germany) maXis, an ESI-ToF MS capable of resolution of at least 40000 FWHM in the group of Prof. Ivana Ivanović-Burmazović, University of Erlangen-Nürnberg.

$\mathrm{X}$-Ray crystal structure determination. Intensity data were measured at a temperature of $120 \mathrm{~K}$ for a single crystal of $[\mathrm{Au}($ terpy $) \mathrm{Cl}]\left(\mathrm{ClO}_{4}\right)_{2}$ on a Bruker Kappa APEX $2 \mathrm{I} \mu \mathrm{S}$ Duo diffractometer using $\mathrm{MoK}_{\alpha}$ radiation (QUAZAR focusing Montel optics, $\lambda=0.71073 \AA$ ). Data were corrected for Lorentz and polarization effects; a semi-empirical absorption correction on the basis of multiple scans was applied (SADABS 2008/1). ${ }^{20}$

\section{Kinetic measurements}

The reaction of $1 \times 10^{-4} \mathrm{M} \mathrm{Au}(\mathrm{III})$ complex with an excess of nucleophile was monitored by UV-Vis spectroscopy over the wavelength range $200-800 \mathrm{~nm}$ at $25^{\circ} \mathrm{C}$. UV-Vis spectra were 
recorded before and after mixing the solutions in the tandem cuvette, to determine the working wavelengths. The progress of the reaction was monitored spectrophotometrically using the stopped-flow apparatus working in the range of the previously determined wavelengths, at appropriate intervals from $5 \mathrm{~ms}$ up to $4 \mathrm{~h}$ (monitored by UV-Vis spectrophotometry). All kinetic runs were carried out with sufficient excess of nucleophile to provide pseudo-first-order conditions. All kinetic traces, each consisting of about one thousand data points, were repeated four to ten times. From the obtained kinetic traces the values of the rate constants $\left(k_{\mathrm{obsd}} / \mathrm{s}^{-1}\right)$ were determined by fitting them to single/double exponential functions (see ESI, Tables S1-S23†). Second order rate constants $\left(k_{1} / \mathbf{M}^{-1}\right.$ $\mathrm{s}^{-1}$ ) were obtained from the slope of plots of $k_{\text {obds }} / \mathrm{s}^{-1}$ versus nucleophile concentration/M (see Fig. 3 and 5 and ESI, Fig. S1-S8†). All results were obtained at $25{ }^{\circ} \mathrm{C}$ and are summarized in Table 1.

\section{Cyclovoltammetric measurements}

The reactions followed by $\mathrm{CV}$ were studied in $0.4 \mathrm{M} \mathrm{NaCl}$ solution as the background electrolyte and the $\mathrm{pH}$ was adjusted to 2.5 or 7 by the addition of diluted $\mathrm{HCl}$ and $\mathrm{NaOH}$ solution. Solutions of $\mathrm{NaClO}_{4}$ and Hepes buffer were not employed because of possible redox reactions that can interfere. The required amount of nucleophile and $\mathrm{Au}(\mathrm{III})$ complex was mixed in different molar ratios $(1: 1,2: 1,20: 1)$ with a final concentration of the $\mathrm{Au}(\mathrm{III})$ complex of $1.00 \mathrm{mM}$. The experiments were repeated at least three times at $25^{\circ} \mathrm{C}$. The obtained data were collected and analyzed using the OriginPro8 and Microsoft Office Excel 2007 programs. Some organosulfur compounds are known to undergo decomposition at the electrode surface with the formation of a gold sulfide film, which inhibits regeneration of the electrode surface. For this reason the working electrode was polished daily or even more often when necessary, prior to use.

\section{${ }^{1}$ H NMR measurements}

${ }^{1} \mathrm{H}$ NMR spectra were recorded in $\mathrm{D}_{2} \mathrm{O}$ at two different $\mathrm{pH}$ values (2.5 and 7), with and without an excess of added chloride. A solution of $20 \mathrm{mM}\left[\mathrm{AuCl}_{4}\right]^{-}$was mixed in different molar ratios with the nucleophiles $(1: 1$ and $1: 3)$ at room temperature. Due to the high reaction rate of the substitution process which is not detectable by NMR, selected data showing the progress of the redox reaction are presented here.

\section{ESI-MS analysis}

The reaction of $\left[\mathrm{AuCl}_{4}\right]^{-}$with L-Cys $(1: 20)$ results in the formation of a white precipitate and a clear solution. The reaction solution was decanted and analyzed since the obtained precipitate was not soluble in water or in methanol. Detection was in the negative and positive-ion mode and the source voltage was $5 \mathrm{kV}$. The flow rates were $180 \mu \mathrm{L} \mathrm{h}{ }^{-1}$. The drying gas $\left(\mathrm{N}_{2}\right)$, to aid solvent removal, was kept at $180{ }^{\circ} \mathrm{C}$. The machine was calibrated prior to every experiment via direct infusion of the Agilent ESI-TOF low concentration tuning mixture, which provided a $\mathrm{m} / \mathrm{z}$ range of singly charged peaks up to $2700 \mathrm{Da}$ in both ion modes.

Table 1 Second-order rate constants $\left(k_{1} / \mathrm{M}^{-1} \mathrm{~s}^{-1}\right)$ for the reactions of the $\left[\mathrm{AuCl}_{4}\right]^{-}$complex and monofunctional Au(III) complexes with thiols (L-cysteine, glutathione) and thioether (L-methionine), at two different $\mathrm{pH}$ values, in the presence of different concentrations of $\mathrm{Cl}^{-}$, at $298 \mathrm{~K}$

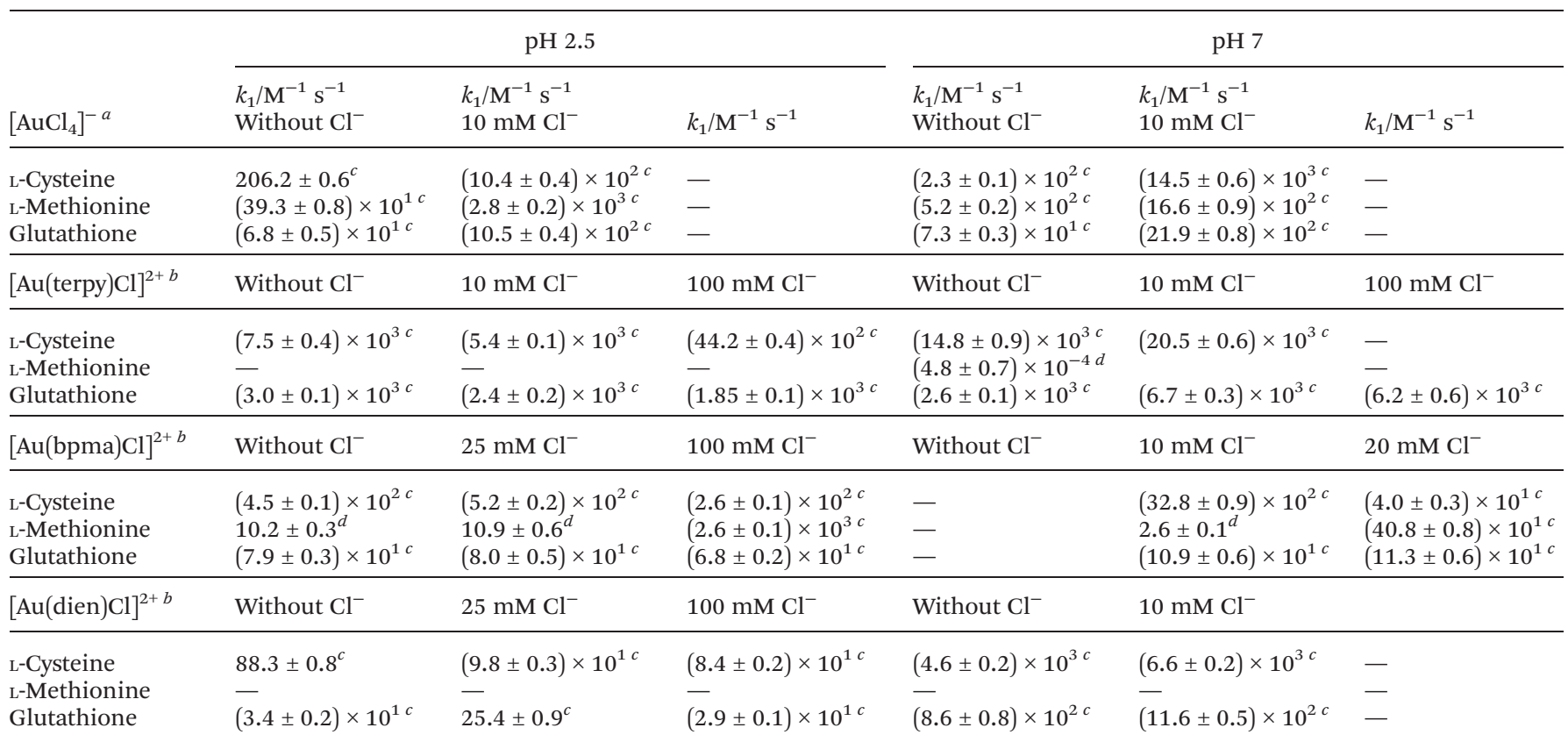

${ }^{a}$ In $0.1 \mathrm{M} \mathrm{NaClO}_{4}$, pH 7; in $\mathrm{HClO}_{4}$, pH 2.5. ${ }^{b}$ In Hepes buffer pH 7; in $\mathrm{HClO}_{4}$, pH 2.5. ${ }^{c}$ Rate constants for the substitution reaction. ${ }^{d}$ Rate constants for the reduction reaction. 


\section{X-Ray crystal structure determination of $[\mathrm{Au}($ terpy $) \mathrm{Cl}]\left(\mathrm{ClO}_{4}\right)_{2}$}

The X-ray suitable crystal was obtained by dissolving the synthesized complex $\left[\mathrm{Au}(\right.$ terpy) $\mathrm{Cl}] \mathrm{Cl}_{2}$ in $0.1 \mathrm{M} \mathrm{NaClO}_{4}$ solution in the presence of $10 \mathrm{mM} \mathrm{Cl}^{-}$, and subsequent slow evaporation. The structure was solved by direct methods and refinement was carried out by full-matrix least-squares procedures on $F^{2}$ with SHELXTL NT 6.12. ${ }^{21}$ All non-hydrogen atoms were refined anisotropically. The crystal under study turned out to be an inversion twin with an approximate twin component ratio of $70: 30$ (see Flack parameter ${ }^{22}$ in Table S24 (ESI $\dagger$ )). All hydrogen atoms were placed in positions of optimized geometry; their isotropic displacement parameters were tied to those of their corresponding carrier atoms by a factor of 1.2 or 1.5 . Further details of the single crystal X-ray structure determination are summarized in Tables S24 and S25 (ESI $\dagger$ ). CCDC-967806 contains the supplementary crystallographic data for this paper.

\section{Results and discussion}

\section{General observations}

All investigated complexes were synthesized with the aim to test the influence of the strong chelating and $\pi$-donation effects of the nitrogen donor tridentate ligands on the stability of the Au(III) center. The reactions of the synthesized complexes with L-methionine (L-Met), L-cysteine (L-Cys) and glutathione (GSH), Fig. 1, in the $2: 1,1: 1$ and $1: 20$ metal : ligand ratios, were studied by different techniques in order to gain as much information as possible on their mechanistic behaviour.

The substitution reactions between the Au(III) complexes and sulfur donor amino acids were studied by UV-Vis spectrophotometry, and the concerted redox reaction was investigated by ${ }^{1} \mathrm{H}$ NMR spectroscopy and cyclovoltammetry (CV). ${ }^{1} \mathrm{H}$ NMR and ESI-MS spectra were used to investigate the oxidation products and to follow the binding ability of the studied thiols and thioether. UV-Vis spectra recorded in a tandem cuvette before and after mixing the solutions of $2 \times 10^{-4} \mathrm{M} \mathrm{Au}(\mathrm{III})$ complex and $2 \times 10^{-2} \mathrm{M}$ amino acids indicate a very fast reaction which was complete within the first minute. Using the stopped-flow technique, it was possible to follow the substitution reactions of the labile $\mathrm{Au}(\mathrm{III})$ complexes with half-lives

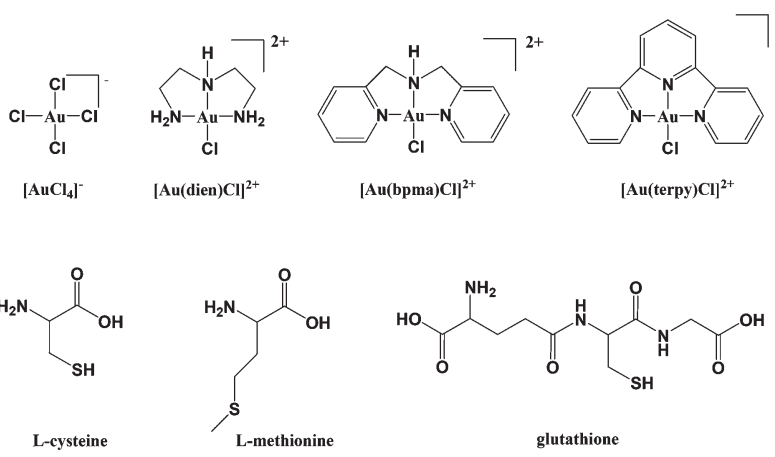

Fig. 1 Structures of the investigated complexes and nucleophiles.
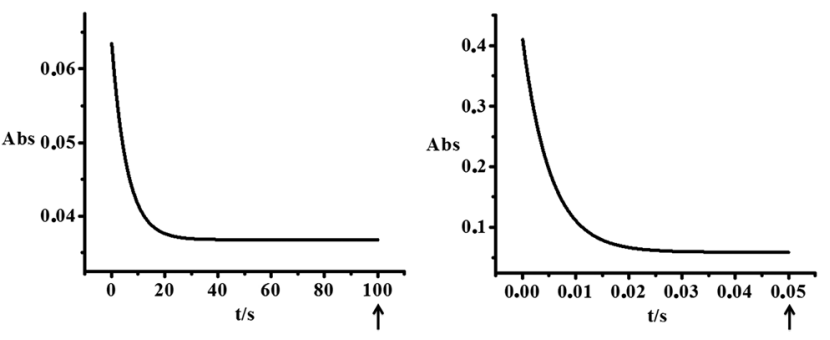

Fig. 2 Typical kinetic traces observed for the reaction of [Au(terpy)Cl] ${ }^{2+}$ with GSH, where the substitution step occurred within $50 \mathrm{~ms}$ (right) and the subsequent reduction reaction within $100 \mathrm{~s}$ (left).

in the millisecond range, accompanied by concerted reduction reactions (see Fig. 2), for which equilibrium constants have been determined previously. ${ }^{23}$ Some representative plots for $k_{\text {obsd }}=\mathrm{f}[\mathrm{Nu}]$, obtained for the substitution step, are shown in Fig. 3 and Fig. S1-S8 (ESI†).

The values of the rate constants obtained at different $\mathrm{pH}(2.5$ and 7), in the presence of different chloride concentrations, are summarized in Table 1. As far as we know, no data seem to be available for the formation of the $\mathrm{Au}(\mathrm{III})-\mathrm{S}$ complexes except for the results obtained from our stopped-flow measurements.

During this study we found that $\left[\mathrm{AuCl}_{4}\right]^{-}$is not stable in $25 \mathrm{mM}$ Hepes buffer, and therefore $0.1 \mathrm{M} \mathrm{NaClO}_{4}$ (for kinetic measurements) or $0.4 \mathrm{M} \mathrm{NaCl}$ (for $\mathrm{CV}$ measurements) solutions were employed for studies at $\mathrm{pH}$ 7. The changes in the UV-Vis spectra observed during the first $30 \mathrm{~min}$ in $25 \mathrm{mM}$ Hepes buffer shown in Fig. $\mathrm{S} 9 \dagger$ are ascribed to the formation of gold nanoparticles, as evidence for $\mathrm{Au}(\mathrm{III})$ reduction
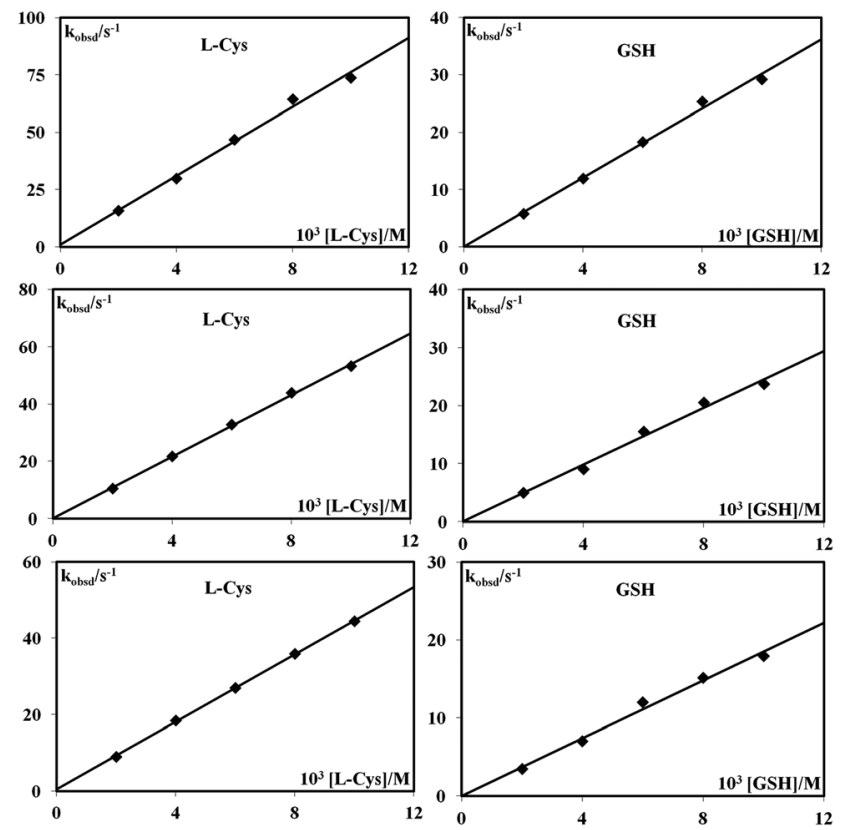

Fig. 3 Pseudo-first-order rate constants plotted as a function of nucleophile concentration for the substitution reactions of the $\left[\mathrm{Au}(\text { terpy) } \mathrm{Cl}]^{2+}\right.$ complex with L-Cys and GSH at pH $2.5\left(0.003 \mathrm{M} \mathrm{HClO}_{4}\right)$, without added chloride (first line), in the presence of $10 \mathrm{mM}$ (second line) and $100 \mathrm{mM}$ chloride (third line) at $298 \mathrm{~K}$. 


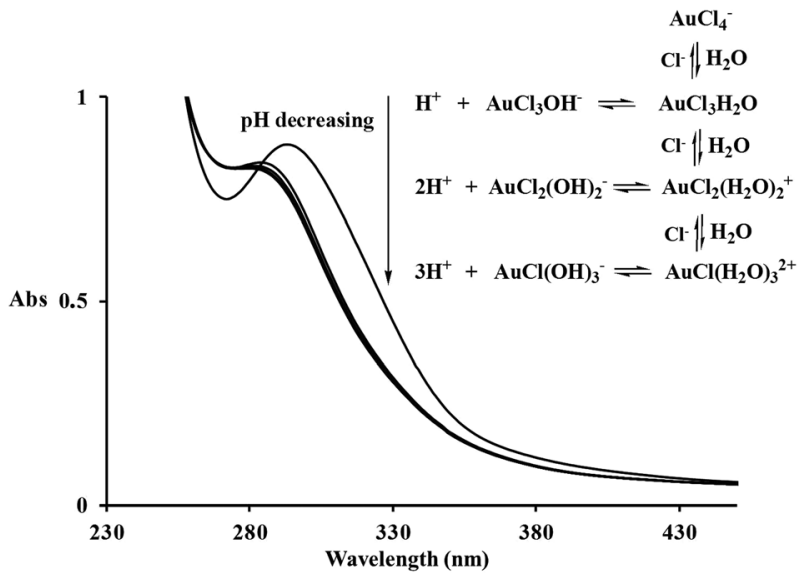

Fig. 4 UV-Vis spectra of $2 \times 10^{-4} \mathrm{M}\left[\mathrm{AuCl}_{4}\right]^{-}$undergoing spontaneous hydrolysis in neutral aqueous solution $\left(0.1 \mathrm{M} \mathrm{NaClO}_{4}\right)$, recorded over $1 \mathrm{~h}$.

accompanied by Hepes oxidation. The ${ }^{1} \mathrm{H}$ NMR spectra of the Hepes buffer in the absence and presence of $\left[\mathrm{AuCl}_{4}\right]^{-}$indicated a characteristic shift which can be ascribed to the oxidation of the Hepes buffer, probably yielding N-oxide similar to the earlier described oxidation by $\mathrm{H}_{2} \mathrm{O}_{2} \cdot{ }^{24}$ This was not observed for the other studied complexes. Even though the $\mathrm{pH}$ of the $0.1 \mathrm{M} \mathrm{NaClO}_{4}$ solution was also 7, the reasonable stability of the $\mathrm{Au}$ (III) observed in Fig. 4 can be explained in terms of a decrease in $\mathrm{pH}$ as the result of spontaneous aquation/ hydrolysis reactions that occur under such conditions. ${ }^{25,26}$

As compared to $\left[\mathrm{AuCl}_{4}\right]^{-}$, all the synthesized monodentate complexes, $[\mathrm{Au}(\mathrm{dien}) \mathrm{Cl}]^{2+},[\mathrm{Au}(\mathrm{bpma}) \mathrm{Cl}]^{2+}$ and $[\mathrm{Au}(\text { terpy }) \mathrm{Cl}]^{2+}$, displayed a higher stability under physiological conditions due to the stabilization induced by the chelate effect of the tridentate ligands surrounding the $\mathrm{Au}(\mathrm{III})$ center and stabilization of $\mathrm{Au}(\mathrm{III})$ against reduction at $\mathrm{pH} 7$.

The initial rapid substitution process resulted in the formation of unstable $\mathrm{Au}(\mathrm{III})-\mathrm{S}$ complexes that were subsequently reduced to $\mathrm{Au}(\mathrm{I} / 0)$ in a slower electron-transfer process. Both $\mathrm{Au}(\mathrm{I})$ and $\mathrm{Au}(\mathrm{III})$ are defined as soft Lewis acids which have a preference for soft S-donor ligands. The fact that soft ligands form more stable complexes with metal ions of low valency, whereas hard ligands show the tendency to bind metal ions of higher valency, ${ }^{27}$ accounts for the observation that $\mathrm{Au}(\mathrm{III})$ complexes with soft ligands can be easily reduced to the $\mathrm{Au}(\mathrm{I})$ state. Soft ligands tend to transfer more electron density to the metal center. Furthermore, substitution of chloride results in the formation of a more positively charged complex, which will show a higher tendency to oxidize the coordinated ligand.

Since $\mathrm{Au}(\mathrm{III})$ chloride complex ions exist in several forms due to hydrolysis in aqueous solution depending on the $\mathrm{pH}^{25,26}$ differences in the rate constants shown in Table 1 were expected. In order to check the influence of added chloride on the observed rate constant, different initial concentrations of chloride were used in the system. For example, the influence of chloride is also obvious from the intercept that decreases with increasing $\mathrm{Cl}^{-}$concentration as seen in Fig. 5, which is ascribed to the suppression of the parallel aquation reaction.
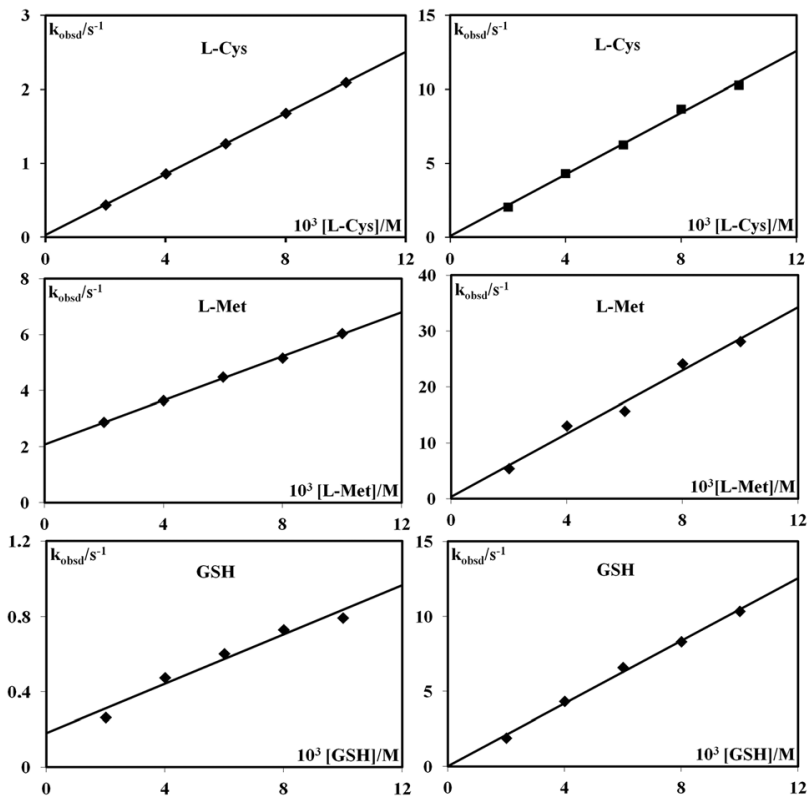

Fig. 5 Pseudo-first-order rate constants plotted as a function of nucleophile concentration for the substitution reactions of the $\left[\mathrm{AuCl}_{4}\right]^{-}$ complex by L-Cys, L-Met and GSH at pH $2.5\left(0.003 \mathrm{M} \mathrm{HClO}_{4}\right)$, without added chloride (left), in the presence of $10 \mathrm{mM}$ chloride (right) at $298 \mathrm{~K}$.

Based on the published distribution of $\mathrm{Au}(\mathrm{III})$-chloride species in solution, ${ }^{26}$ and the fact that aqua species do not exist in aqueous solution, ${ }^{28}$ we assume that $\left[\mathrm{Au}(\mathrm{OH}) \mathrm{Cl}_{3}\right]^{-}$is the dominant species at $\mathrm{pH} 2.5$, whereas $\left[\mathrm{Au}(\mathrm{OH})_{3} \mathrm{Cl}\right]^{-}$at $\mathrm{pH} 7$. From this comparison it can be evaluated that at a higher $\mathrm{pH}$ the substitution reaction of chloride is accelerated because of the relative inertness of the $\mathrm{Au}(\mathrm{III})-\mathrm{OH}$ bond and its cis/trans influence on the lability of the coordinated chloride ligand(s). The lability of coordinated hydroxide depends on the nature of the gold ion, ranging from very inert for hydroxide bound to $\mathrm{Au}(\mathrm{III})$ to highly labile for hydroxide bound to $\mathrm{Au}(\mathrm{I})$. Therefore, further reduction of $\left[\mathrm{Au}(\mathrm{OH})_{2}\right]^{-}$can be explained in terms of substitution by chloride and formation of chloride bridged species responsible for electron transfer reactions, ${ }^{29}$ as well as by the well-known disproportionation of $\mathrm{Au}(\mathrm{I}), v i z .3 \mathrm{Au}(\mathrm{I}) \rightarrow$ $\mathrm{Au}(\mathrm{III})+2 \mathrm{Au}^{0} .^{30,31}$ Although $\mathrm{Au}(\mathrm{I})$ species are known to be stable against reduction, this is not the case in the present system where reduction is already initiated, see Scheme 1.

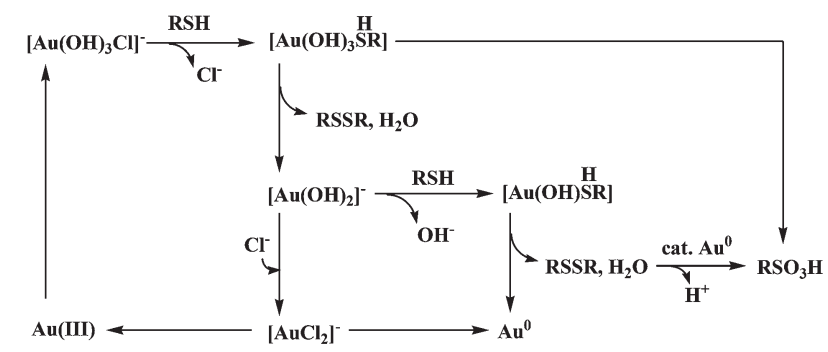

Scheme 1 Proposed reaction pathways for the interaction of gold(III) ions with thiols/thioethers. 


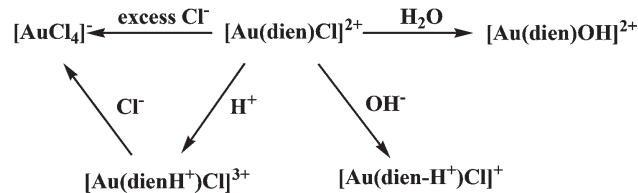

Scheme 2 Influence of the reaction conditions on the formation of different reaction species of the $[\mathrm{Au}(\mathrm{dien}) \mathrm{Cl}]^{2+}$ complex.

Since perchlorate is considered to be an oxidant, the rate constants obtained for the reactions of $\left[\mathrm{AuCl}_{4}\right]^{-}$cannot be directly compared to values obtained for the other complexes. The synthesized complexes also occur in different reactive forms as a function of $\mathrm{pH}$, see Scheme 2. The $\mathrm{pH}$ values of the solutions employed in this study partially arise from the fact that gold(III) chelate complexes undergo ring-opening at $\mathrm{pH}<$ 2.5. ${ }^{32}$ Furthermore, the addition of an excess of chloride ions enhances the stability of such complexes and can influence the rate of reduction, as well as lead to the formation of $\left[\mathrm{AuCl}_{4}\right]^{-}$via displacement of the chelate ligand by chloride at low $\mathrm{pH}^{33}$

According to the $\mathrm{p} K_{\mathrm{a}}$ values of $\left[\mathrm{Au}(\mathrm{dien}) \mathrm{Cl}^{2+}\right.$ and $\left[\mathrm{Au}(\mathrm{bpma}) \mathrm{Cl}^{2+}\right]^{2+0}$ and 3.5 , respectively, ${ }^{18,34}$ for the coordinated chelate), it is expected that at $\mathrm{pH} 6-7$ ligand deprotonation has fully occurred. Thus the stronger trans influence of the amido complex causes a faster substitution reaction than that found at pH 2.5 (see Table 1), where the lower donor strength of $\mathrm{NH}$ in comparison to $\mathrm{N}^{-}$induces a shorter $\mathrm{Au}-\mathrm{Cl}$ bond and therefore lower substitution rate constants.

From the obtained crystal structure of $[\mathrm{Au}($ terpy $) \mathrm{Cl}]\left(\mathrm{ClO}_{4}\right)_{2}$ it is obvious that $10 \mathrm{mM} \mathrm{Cl}^{-}$can suppress the solvolysis, as well as that the perchlorate ion does not coordinate to $\mathrm{Au}(\mathrm{III})$ in aqueous solution, Fig. S10 and Tables S24-S25 (ESI†). Since Pitteri reported that the $\mathrm{p} K_{\mathrm{a}}$ of the corresponding aqua complex is 0.1 , it can be expected that in the absence of an excess of chloride ions, the dominant species in solution will be $[\mathrm{Au}(\mathrm{terpy}) \mathrm{OH}]^{2+}{ }^{35}$ Even though chloride is less strongly bonded and the kinetics are faster, the results summarized in Table 1 in some cases show the opposite trend. In the presence of chloride, the formation of chloride bridged species can be responsible for the acceleration of the redox reaction, but slows down the substitution step when compared to solutions without an excess of chloride ions. ${ }^{29}$ Increasing the basicity of the nitrogen donor of the coordinated ligand increases the stability of the Au-N bond by a few orders of magnitude. Since both substitution and reduction occur to give the final product, both accompanied by absorbance changes in the same direction, it was not possible to observe the first step as long as the substitution was not fast enough. The redox rate constants were observed to decrease with increasing $\mathrm{pH},{ }^{36}$ such that substitution could be observed at $\mathrm{pH} 7$ due to the slow concerted reduction under such conditions.

\section{Reactions with L-methionine}

The reaction between $1 \times 10^{-4} \mathrm{M}\left[\mathrm{AuCl}_{4}\right]^{-}$and 20 to 100 fold excess of L-Met was followed spectrophotometrically by measuring the change in absorbance at a fixed, previously determined wavelength as a function of time. These changes occur as the new complex formed by reduction of $\mathrm{Au}$ (III) to $\mathrm{Au}(\mathrm{I})$, and $\mathrm{Au}(\mathrm{I})$ to $\mathrm{Au}(0)$, undergoes ligand exchange between chloride ions and the sulfur donor nucleophile according to Scheme 1. The rate constant $k_{1}=393 \pm 8 \mathrm{M}^{-1} \mathrm{~s}^{-1}$ at $25{ }^{\circ} \mathrm{C}$ was determined for the ligand substitution reaction; however, the reaction proceeds more rapidly when the chloride concentration is $10 \mathrm{mM}$ in both acidic and neutral media, see Table 1. This can be ascribed to the stabilization of the chloride gold(III) complex.

The course of this reaction with the thioether in the molar ratios of $1: 1$ and $1: 20$ (Au: $\mathrm{L}-\mathrm{Met}$ ) in aqueous solution in the presence of $0.4 \mathrm{M}$ chloride ions was followed using $\mathrm{CV}$ and ${ }^{1} \mathrm{H}$ NMR. The CV of a $1 \mathrm{mM}$ solution of $\left[\mathrm{AuCl}_{4}\right]^{-}$in $0.003 \mathrm{M} \mathrm{HCl}$ in the presence of $0.4 \mathrm{M} \mathrm{NaCl}$ as a background electrolyte recorded for a GC electrode upon reaction with an equimolar concentration of $\mathrm{L}-\mathrm{Met}$ displayed a shift of the cathodic peak from A $(0.37 \mathrm{~V})$ to B $(0.42 \mathrm{~V})$, see Fig. 6 , which is evidence for the reduction of $\mathrm{Au}(\mathrm{III})$ to $\mathrm{Au}(\mathrm{I})$ and formation of an $\mathrm{Au}(\mathrm{I})$ complex. ${ }^{37}$ In the case of an excess of L-Met, the cathodic peak $\mathrm{B}$ is not detectable anymore due to faster reduction, induced by a very fast substitution reaction. For the reverse sweep, clear oxidation waves were observed, but are not described here because of the influence of numerous oxidation steps that can possibly occur. ${ }^{38-40}$ Due to the precipitation of elemental gold, the electrode surface was not active anymore. When $\left[\mathrm{AuCl}_{4}\right]^{-}$ and L-Met were mixed in 1:1 or 1:20 molar ratios at $\mathrm{pH}$, and reactions were performed under the above-mentioned conditions, similar results were obtained.

As reported in Fig. S11 (ESI†), which shows the ${ }^{1} \mathrm{H}$ NMR spectra for the reaction of $10 \mathrm{mM}\left[\mathrm{AuCl}_{4}\right]^{-}$with $10 \mathrm{mM} \mathrm{L}-\mathrm{Met}$ in aqueous solution ( $\mathrm{pH} 7$ ), the initial 2.13 and 2.64 ppm resonances of the $\mathrm{CH}_{3}$ and $\mathrm{CH}_{2}$ groups bonded to sulfur, respectively, were replaced by resonances at 2.79 and $3.20 \mathrm{ppm}$, respectively. These changes in the chemical shift are in the
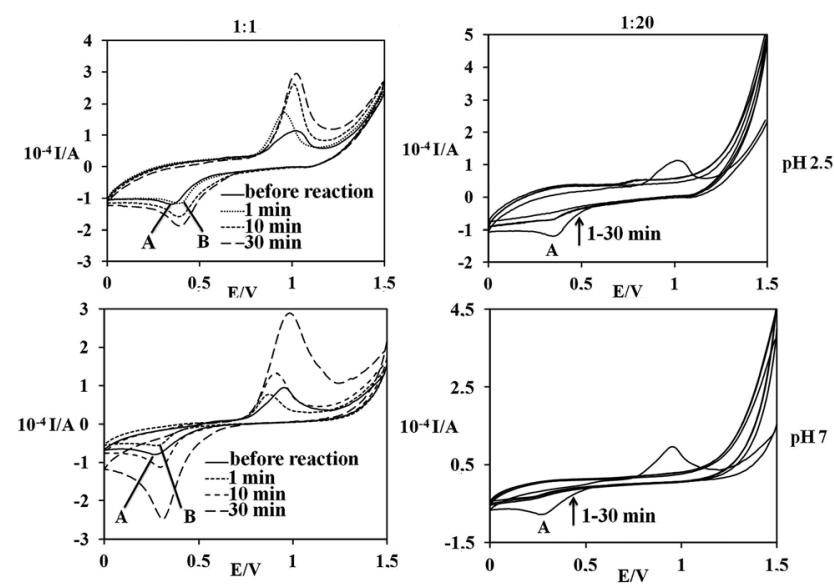

Fig. 6 Cyclic voltammograms recorded during the progress of the reaction between $\left[\mathrm{AuCl}_{4}\right]^{-}$and L-Met, at different complex : L-Met molar ratios, at two $\mathrm{pH}$ values; $\mathrm{GC}$ electrode, scan rate $0.1 \mathrm{~V} \mathrm{~s}^{-1}, E_{\text {step }}=0.01 \mathrm{~V}$, $0.4 \mathrm{M} \mathrm{NaCl}$ as the background electrolyte. 
direction of the formation of methionine sulfone over methionine sulfoxide, which is in agreement with the acidity of the solution at the end of the reaction ( $\mathrm{pH}$ 1.54). Such a high concentration of $\mathrm{H}^{+}$ions as well as participation of elemental gold as a catalyst, or even paramagnetic nanoparticles, can account for the up-field shift of these signals during overnight monitoring. Since the oxidation products of L-methionine are methionine sulfoxide and sulfone, we assume that the intermediate $\mathrm{Au}(\mathrm{I})$ cannot coordinate to sulfoxide; therefore signals of the coordinated oxidized product did not appear. The nonbonding electrons of the sulfur atom, which form bonds with electrophiles such as metal ions, are responsible for the redox reaction, whereas participation of the water molecule in the redox process was already assumed and leads to the formation of $\mathrm{H}_{3} \mathrm{O}^{+}$ions. ${ }^{14}$ Furthermore, the most significant effect of changing the acidity of the reaction solution is the appearance of the cathodic signal during the CV study at $-1.08 \mathrm{~V}$, which corresponds to the conditions of a low $\mathrm{pH}$ value (see Fig. S12, ESI $\dagger)^{41}$

No significant spectral changes were observed for the reaction between $\left[\mathrm{Au}(\right.$ dien $) \mathrm{Cl}^{2+}$ and $\mathrm{L}-\mathrm{Met}$ for $1 \mathrm{~h}$ at room temperature, based on the recorded UV-VIS spectra. The minor spectral changes that are generally observed within the first hour may be ascribed to the progressive hydrolysis of $\mathrm{Au}(\mathrm{III})$ bound chloride, leading to the formation of polynuclear complexes. Compared to the other studied nucleophiles, L-Met does not seem to be efficient enough to reduce a polynuclear complex of gold(III).

For the reaction of $[\mathrm{Au}(\mathrm{bpma}) \mathrm{Cl}]^{2+}$ with $\mathrm{L}-\mathrm{Met}$, the substitution step is only observed in the case of $100 \mathrm{mM}$ chloride, which could be an indication of the formation of $\left[\mathrm{AuCl}_{4}\right]^{-}$in the presence of a large excess of chloride. The other values of the rate constant obtained in the presence of different chloride concentrations for the $[\mathrm{Au}(\mathrm{bpma}) \mathrm{Cl}]^{2+}$ complex, see Table 1, point to domination of the reduction process.

In agreement with the earlier reported results that metalterpyridine complexes do not undergo substitution reactions with thioethers, ${ }^{42}$ similar results were obtained in this study. UV-Vis spectra recorded for a tandem reaction of [Au(terpy)$\mathrm{Cl}]^{2+}$ and L-Met in the 1:100 molar ratio at $\mathrm{pH} 2.5$ and 7 showed that the reaction proceeds really slowly and yields the free terpyridine ligand, see Fig. 7. Strong absorption bands with maxima at 288 and $323 \mathrm{~nm}$ correspond to $\left[\mathrm{H}_{2}\right.$ terpy $\left.^{2+}\right]$ $\left(\mathrm{p} K_{\mathrm{a} 1}=2.6, \mathrm{p} K_{\mathrm{a} 2}=4.2\right),{ }^{43}$ whereas a broad band at $283 \mathrm{~nm}$ is characteristic of [terpy]. ${ }^{4,45}$
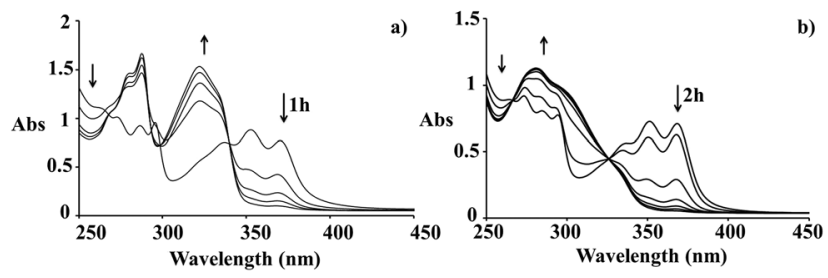

Fig. 7 Spectral changes observed during the reaction of $1 \times 10^{-4} \mathrm{M}$ $\left[\mathrm{Au}\left(\right.\right.$ terpy)Cl] ${ }^{2+}$ and $1 \times 10^{-2} \mathrm{M}$ L-Met, at different pH: (a) 2.5 and (b) 7.

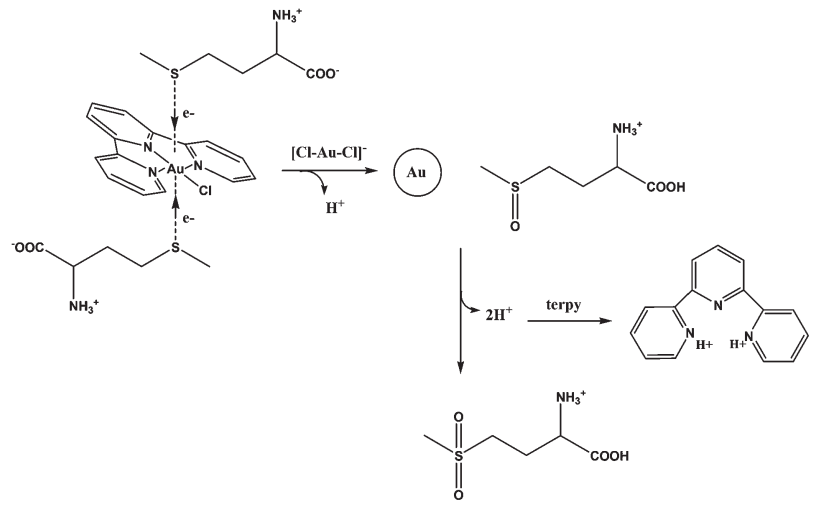

Scheme 3 Suggested mechanism for the reduction of $[\mathrm{Au}(\operatorname{terpy}) \mathrm{Cl}]^{2+}$ by L-Met.

To explain the reduction in this system, we suggest a mechanism that involves outer-sphere electron transfer via the axial positions in a pseudo-octahedral complex, Scheme 3. The presence of a buffer system, including protonation of the tridentate ligands, can account for the stable $\mathrm{pH}$ values mentioned above.

The value of the rate constant for the electron transfer reaction $\left(k_{\mathrm{ET}}\right)$ is $(4.8 \pm 0.7) \times 10^{-4} \mathrm{M}^{-1} \mathrm{~s}^{-1}$, which is obtained from eqn (1), see Fig. 8:

$$
k_{\mathrm{obsd}}=\frac{k_{\mathrm{ET}} K[\mathrm{Nu}]}{1+K[\mathrm{Nu}]}
$$

\section{Reactions with L-cysteine}

With the aim to check the stability of the newly synthesized $\mathrm{Au}(\mathrm{III})$ complexes with thiols under physiological conditions and to detect possible reaction products, different $\mathrm{Au}(\mathrm{III})$ : L-Cys molar ratios were studied. CVs were recorded for the reduction process as shown in Fig. S13, ESI. $\dagger$ In the negative backward scan, a characteristic current peak for $\mathrm{Au}$ (III) was formed at $0.37 \mathrm{~V}$. During the first minute of the reaction between $\left[\mathrm{AuCl}_{4}\right]^{-}$and $\mathrm{L}_{\text {-Cys }}(1: 1)$, it was possible to detect a shift to a more positive potential. The signal at $0.42 \mathrm{~V}$ is suggested to be

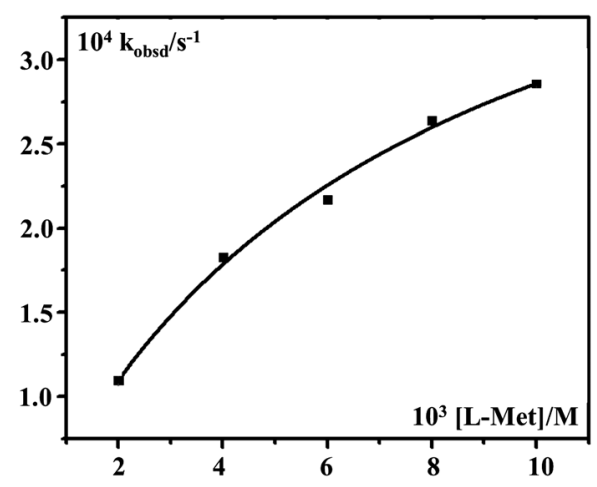

Fig. 8 Pseudo-first-order rate constants plotted as a function of nucleophile concentration for the outer-sphere redox reaction of the $\left[\mathrm{Au}(\right.$ terpy $) \mathrm{Cl}^{2+}$ complex with L-Met at pH 7 (25 mM Hepes buffer, without added chloride), $298 \mathrm{~K}$. 


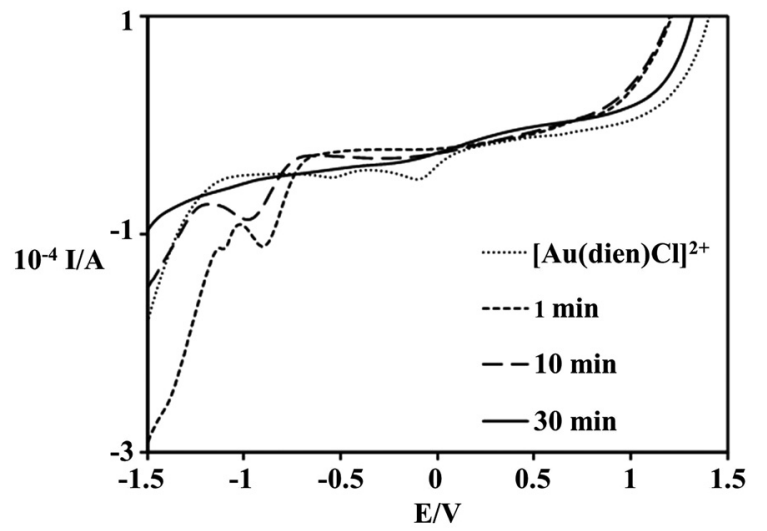

Fig. 9 Cyclic voltammograms recorded for the reaction between $1 \mathrm{mM}$ $\left[\mathrm{Au}\right.$ (dien) $\mathrm{Cl}^{2+}$ and $20 \mathrm{mM} \mathrm{L-Cys} \mathrm{at} \mathrm{pH} 7$, in $0.4 \mathrm{M} \mathrm{NaCl}$ as the background electrolyte, GC electrode.

an indication of $\mathrm{Au}(\mathrm{I})$ complex formation. A very strong effect was recorded for the $1: 2$ and $1: 20$ molar ratios that corresponded to complete degradation leading to metallic gold. From Table 1 it is obvious that the rate constants for the substitution reaction at $\mathrm{pH} 7$ are ten times higher than those at $\mathrm{pH} 2.5$, and therefore the reduction is completed in the first minute; thus the signal corresponding to $\mathrm{Au}(\mathrm{I})$ formation was not observed.

In Fig. 9 it is shown that the formal potential of $\mathrm{Au}(\mathrm{III}) /$ $\mathrm{Au}(0)$ becomes more negative on comparing $[\mathrm{Au}(\text { dien }) \mathrm{Cl}]^{2+}$ and $\left[\mathrm{AuCl}_{4}\right]^{-}$. The shift towards a more negative potential indicates a higher stability of the complex, which was expected. Thus, the dien ligand stabilizes the $\mathrm{Au}(\mathrm{III})$ center more than the $\mathrm{Cl}^{-}$ ions.

Scanning the potential toward more negative values $(+1.5$ to $-1.5 \mathrm{~V}$ ) yielded an intense reduction peak at $-1.08 \mathrm{~V}$ that is not present during the scanning in neutral solution, see Fig. S14, ESI. $\dagger$ Disulfide formation via reductive elimination from two adjacent L-Cys species resulted in the formation of $2 \mathrm{H}^{+}$ions and a decrease in $\mathrm{pH}$. From the CVs obtained for the reaction of $[\mathrm{Au}(\mathrm{dien}) \mathrm{Cl}]^{2+}$ with $\mathrm{L}$-Cys, it can be seen that during the reaction an intense signal appears at $c a$. $-0.9 \mathrm{~V}$ as the $\mathrm{pH}$ is lowered to 2 , but then it disappears, which is not observed in the case of L-Met, see Fig. S14, ESI. $\uparrow$ The small decrease in peak intensity was probably due to the competing process of the formation of a cysteine layer on the electrode, which indicated that thiols show a higher tendency to decompose on the electrode surface than thioethers. ${ }^{46,47}$

In a tandem cuvette reaction of $[\mathrm{Au}(\text { terpy }) \mathrm{Cl}]^{2+}$ with L-Cys in the molar ratio $1: 20$, the characteristic spectrum of the complex is displaced by two intense bands centered at 288 and $324 \mathrm{~nm}$, see Fig. 10. Similar to the reaction with L-Met, these spectra agree well with those known from the literature and confirm the presence of the free terpyridine ligand at $\mathrm{pH}$ 1-4 in the studied system. ${ }^{41}$ Additional scanning during the time shows the appearance of a characteristic broad band of higher intensity in the range between 350 and $450 \mathrm{~nm}$, due to further oxidation of the amino acid, see Fig. 10.

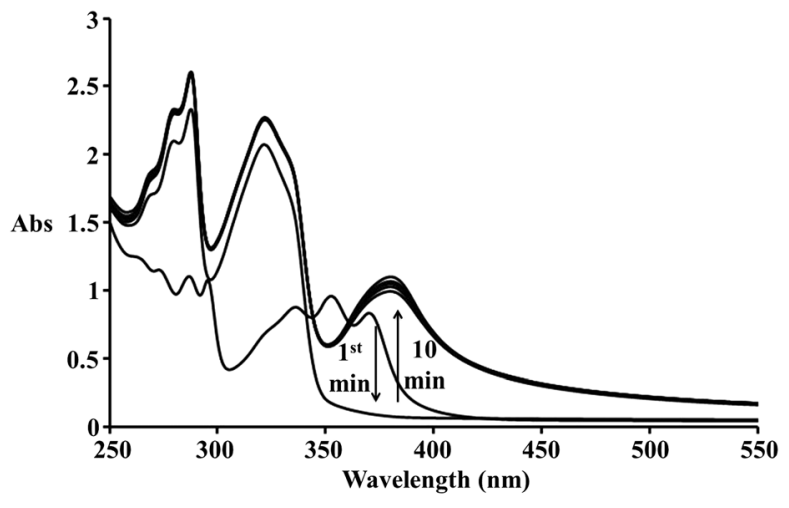

Fig. 10 Spectral changes recorded during the reaction of $1 \times 10^{-4} \mathrm{M}$ $[\mathrm{Au} \text { (terpy)Cl] }]^{2+}$ and $1 \times 10^{-2} \mathrm{M} \mathrm{L-Cys}$ at $\mathrm{pH} 2.5$; evidence for further oxidation of the disulfide bond.

It is well known that oxidation of L-Cys leads to the formation of different products, which in this study were detected by ${ }^{1} \mathrm{H}$ NMR spectroscopy and ESI-MS as well, see Fig. 11 and 12, respectively. As disulfides are more resistant to oxidation, they usually require a stronger oxidant, excess oxidant, higher temperature or a catalyst. The ability of gold to cleave the disulfide bond in Cys-disulfide, as well as to act as a catalyst, may explain further the oxidation that leads to the formation of sulfonic acid. In addition, it is well known that at $\mathrm{pH}<2$, L-Cys gives cysteic (cysteine sulfonic) acid. ${ }^{36}$ The final $\mathrm{pH}$ value of the solution is 1.31 , which is in agreement with the formation of sulfonic acid. The progressive downfield shifts upon oxidation of a thiol group to disulfide could be accounted for by a decrease of the electron density on sulfur, followed by the drastic influence of the decrease in $\mathrm{pH}$.

The course of the reaction of $10 \mathrm{mM}\left[\mathrm{AuCl}_{4}\right]^{-}$with $30 \mathrm{mM}$ L-Cys in aqueous solution was also followed using ${ }^{1} \mathrm{H}$ NMR. Based on a comparison of the results with those obtained previously, it would be reasonable to expect that oxidation of the thiol group may proceed through the formation of disulfide, while all final products cannot be detected by ${ }^{1} \mathrm{H}$ NMR since some of them appear to be a precipitate. The appearance of the two groups of signals, where both are less low field shifted than expected, indicates the formation of two different and

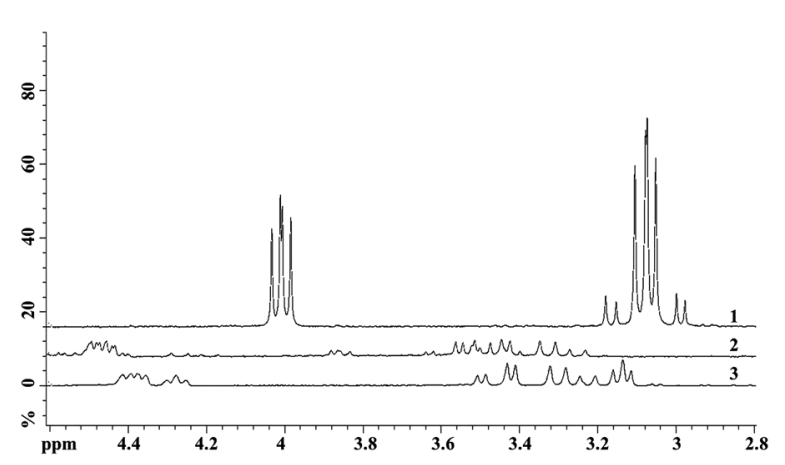

Fig. 11 A comparison of the ${ }^{1} \mathrm{H}$ NMR spectra recorded for: (1) L-Cys; (2) the reaction of an equimolar amount of $\left[\mathrm{AuCl}_{4}\right]^{-}$and L-Cys; (3) the reac-

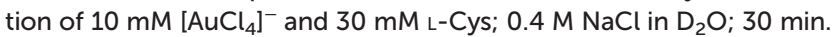




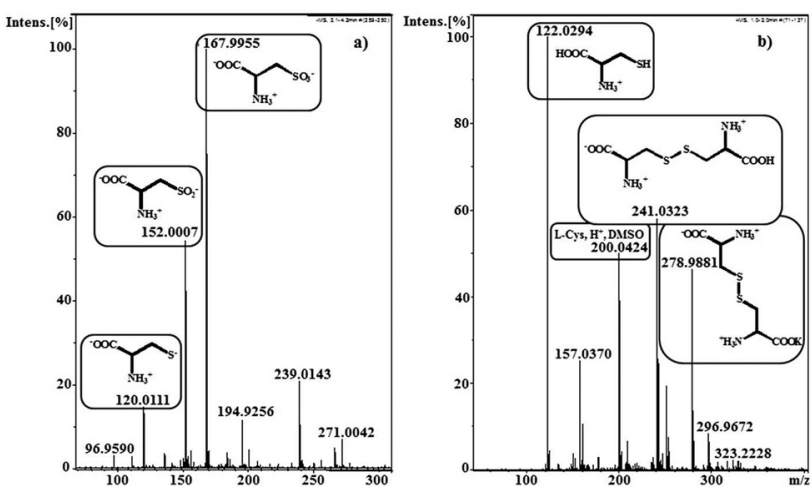

Fig. 12 Representative ESI-MS spectra as evidence for complete L-Cys oxidation in the reaction with $\left[\mathrm{AuCl}_{4}\right]^{-}$; products are detected as (a) negative and (b) positive ion mode.

also differently soluble products. Under this condition, it could be Cys-disulfide and cysteinesulfonic acid.

Furthermore, ESI-MS spectra for the reaction of $\left[\mathrm{AuCl}_{4}\right]^{-}$ with L-Cys (1:20 molar ratio, respectively), shown in Fig. 12, contain signals at $\mathrm{m} / \mathrm{z} 167.96$ and 152.00 , which correspond to the cysteinesulfonic acid anions $(\mathbf{1}, \mathbf{2})$, the signals at $\mathrm{m} / \mathrm{z}$ 120.01 and 122.03 corresponding to the L-Cys anion (3) and cation (4), as well as those at $\mathrm{m} / \mathrm{z} 241.03$ and 278.99 which correspond to Cys-disulfides $(\mathbf{5}, \mathbf{6})$. A similar spectrum was obtained for the reaction of equimolar amounts of the gold(III) complex and L-Cys, and is therefore not presented here. Since we were not able to analyze the reaction precipitate, we suggest that it contains the less soluble product of L-cysteine oxidation, such as sulfone and sulfonate, and even more L-cysteine coordinated to $\mathrm{Au}(\mathrm{I})$. Finally, a possible reaction mechanism, presented in Scheme S1, ESI, $\uparrow$ can offer an explanation for the formation of the reaction products, similar to Scheme 1.

\section{Reactions with glutathione}

Similar to the earlier described reactions of $\mathrm{Au}(\mathrm{III})$, interaction with glutathione was also investigated by UV-Vis, CV and ${ }^{1} \mathrm{H}$ NMR techniques. By measuring the absorbance change at a specific wavelength, the first-order rate constant, $k_{\text {obsd, }}$, was determined for the substitution reaction between some of the investigated complexes and the cysteine residue of GSH. The expected influence of an excess of chloride ions, as well as the $\mathrm{pH}$ value of the reaction solution, resulted in comparable values of the rate constants, $k_{1}$, for the reaction of $\left[\mathrm{AuCl}_{4}\right]^{-}$ with GSH. Since the $\mathrm{p} K_{\mathrm{a}}$ of a thiol group is 6 and the $\mathrm{pH}$ of the solution determines the position of the thiol/thiolate equilibrium, very slow rate constants can be attributed to the effect of a low $\mathrm{pH}$ (2.5) on the nucleophilicity of the thiol group. Hydrolysis of $\left[\mathrm{AuCl}_{4}\right]^{-}$in the reaction without an excess of chloride induces a lower $\mathrm{pH}$ than 7 , which could be the reason for the similar rate constants obtained at $\mathrm{pH} 2.5$ and 7 , viz. $68 \pm 5$ and $73 \pm 3 \mathrm{M}^{-1} \mathrm{~s}^{-1}$, respectively.

The first scan after mixing the reactants $\left[\mathrm{Au}(\right.$ terpy $) \mathrm{Cl}^{2+}$ and GSH exhibits an intense absorbance in the range between 250 and $390 \mathrm{~nm}$, which corresponds to the free terpyridine ligand at a different $\mathrm{pH}$, similar to the spectra obtained in the reaction with L-Cys and L-Met. This indicates that the products of the substitution and redox reactions were formed within the time of mixing of the reactants. A very fast consecutive reduction reaction was indicated by an absorbance increase in the range $>350 \mathrm{~nm}$ that corresponds to the product of further oxidation of GSH, see Fig. S15 (ESI†).

The low rate constants found for the substitution reaction for the $[\mathrm{Au}(\mathrm{bpma}) \mathrm{Cl}]^{2+}$ and $[\mathrm{Au}(\mathrm{dien}) \mathrm{Cl}]^{2+}$ complexes once again prove that the chelate effect and stabilization of the $\mathrm{Au}$ (III) center induced by terpyridine are much stronger than those in the case of the bpma and dien tridentate ligands. Therefore, the higher lability of $[\mathrm{Au}(\text { terpy }) \mathrm{Cl}]^{2+}$ made the substitution reaction visible prior to the reduction step.

Cyclic voltammetry was also employed to monitor this reaction. As the reaction of $\left[\mathrm{AuCl}_{4}\right]^{-}$and an equimolar amount of GSH proceeded, a cathodic peak at $0.33 \mathrm{~V}$ was detected that corresponded to the formation of an $\mathrm{Au}(\mathrm{I})$ complex, but its intensity decreased during the time of the reaction, see Fig. S16 (ESI $\dagger$ ). As in the case of the other employed thiol and thiolate described above, an excess of GSH also leads to complete reduction of $\mathrm{Au}(\mathrm{III})$ to $\mathrm{Au}(0)$, followed by the formation of a GSH monolayer on the electrode surface.

Treatment of $\mathrm{Au}(\mathrm{III})$ with $\mathrm{GSH}$ in different molar ratios resulted in the formation of the same product. The most important reaction of the disulfide bond is its cleavage, which proceeds much faster than the reduction, ${ }^{48}$ and leads to the formation of $\mathrm{GSO}_{3}{ }^{-}$. Due to the already reported observation that glutathione sulfonic acid is not observed at $\mathrm{pH}>4,{ }^{36}$ we can conclude that it is the product of the oxidation of GSH by $\mathrm{Au}(\mathrm{III})$, which is in agreement with the final acidity of the reaction mixture ( $\mathrm{pH}$ 1.66). When ${ }^{1} \mathrm{H}$ NMR is used to monitor this reaction, all signals are shifted downfield, which is indicative of disulfide and sulfonic acid formation, Fig. S17 (ESI $\dagger$ ), whereas the signals for sulfoxide and sulfone formation were undetectable due to their low solubility. The addition of increasing concentrations of GSH induced the appearance of new signals, which indicate that in solution we might have GSSG, as well as $\mathrm{GSO}_{3}{ }^{-}$, as the only soluble species. These results indicate similar reaction intermediates to those described for the other thiols above.

Even upon addition of an excess of $\mathrm{Au}(\mathrm{III})$, there are similar changes in the UV-Vis spectrum that correspond to the formation of free terpyridine, but not in a few minutes. At this molar ratio the reaction is completed in 3-5 days, see Fig. S18 (ESI†). In order to slow down the redox reaction or to even suppress it in blood during medical therapy, a higher concentration level of gold could be selected. It typically reaches 20 $\mu \mathrm{M}$, which is still low in comparison to the concentration of GSH in the cell that is up to $10 \mathrm{mM}^{49}$

Due to the fact that $\mathrm{Au}(\mathrm{III})$ complexes behave as strong oxidizing agents and are quickly reduced to $\mathrm{Au}(\mathrm{I})$ or colloidal gold that still shows biological activity, ${ }^{50-53}$ we can account for this in terms of the formation of two to three active species in vivo: viz. $\mathrm{Au}(\mathrm{I})$ and free ligand with proven activity, ${ }^{54,55}$ and elemental Au with possible surface interaction with DNA ${ }^{56}$ while the 


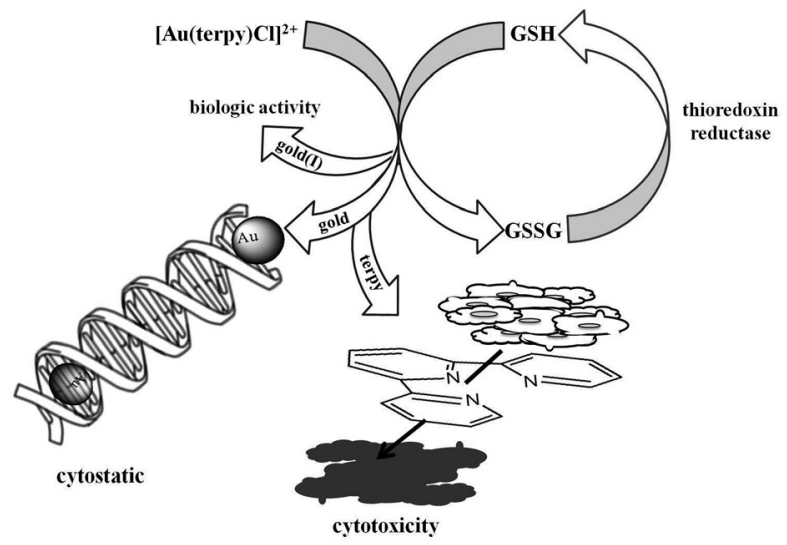

Scheme 4 Explanation offered for the activity of the Au(III) complex in vivo; three-fold activity of the $\left[\mathrm{Au}(\text { terpy) } \mathrm{Cl}]^{2+}\right.$ complex against tumor cells.

oxidation products of GSH (GSSG) could be reduced by the activity of the glutathione reductase enzyme, see Scheme 4 . Therefore, this mechanism deserves to be underlined.

\section{Conclusions}

We have shown that in the investigated complexes the oxidizing properties of $\mathrm{Au}(\mathrm{III})$ are drastically decreased by the presence of a multidentate ligand in such a way that a ligand substitution reaction was detectable. In the presence of biologically relevant thiols and thioether, they undergo irreversible redox reactions. The mechanism can be described as competition between substitution and redox reactions, in which the coordinated inert ligands and the nucleophiles play the most important role to make substitution "visible" prior to reduction. The first ligand substitution reaction occurs very fast and can only be detected by the stopped-flow technique.

Cyclovoltammetry was useful to detect $\mathrm{Au}(\mathrm{I})$ as an intermediate species, while the final oxidation products of L-Cys, L-Met and GSH were detected by NMR spectroscopy. ESI-MS spectra of the L-Cys oxidation product confirmed our assumption that it leads to cysteinesulfonic acid formation.

It should be noted that even though the initial substitution step is very similar, it is certain that their mode of action will be different from that of $\mathrm{Pt}$ (II) complexes. The previously observed cytotoxic effect may well arise from in vivo reduction of the complex followed by the action of $\mathrm{Au}(\mathrm{I})$ and elemental gold, as well as by the free ligand itself.

\section{Acknowledgements}

The authors gratefully acknowledge financial support from the Ministry of Science and Technological Development of the Republic of Serbia (project no. 172011), the Deutsche Forschungsgemeinschaft and DAAD. We would also like to thank
Dipl.-Chem. Oliver Troeppner (University of Erlangen-Nürnberg) for his help and advice on the ESI-MS measurements.

\section{References}

1 J. R. Ward, Am. J. Med., 1988, 85, 39.

2 P. J. Sadler and R. E. Sue, Metal-Based Drugs, 1994, 1, 107.

3 M. Navarro, Coord. Chem. Rev., 2009, 253, 1619.

4 C. E. Housecroft and A. G. Sharp, Inorganic Chemistry, Essex, England, 2001, ch. 22.

5 E. R. Stadtman, H. Van Remmen, A. Richardson, N. B. Wehr and R. L. Levine, Biochim. Biophys. Acta, 2005, 1703, 135.

6 C. Jacob, G. I. Giles, N. M. Giles and H. Sies, Angew. Chem., Int. Ed., 2003, 42, 4742.

7 R. G. Pearson, J. Am. Chem. Soc., 1963, 85, 3533.

8 G. Marcon, L. Messori, P. Orioli, M. A. Cinellu and G. Minghetti, Eur. J. Biochem., 2003, 270, 4655.

9 L. Messori, G. Marcon and P. Orioli, Bioinorg. Chem. Appl., 2003, 1, 177.

10 I. Ott, Coord. Chem. Rev., 2009, 253, 1670.

11 S. L. Best and P. J. Sadler, Gold Bull., 1996, 29, 87.

12 B. A. Al-Maythalony, M. I. M. Wazeer and A. A. Isab, Inorg. Chim. Acta, 2010, 363, 3244.

13 E. Bordignon, L. Cattalini, G. Natile and A. Scatturin, J. Chem. Soc., Chem. Commun., 1973, 878.

14 G. Natile, E. Bordignon and L. Cattalini, Inorg. Chem., 1976, 15, 246.

15 A. Ericson, L. I. Elding and S. K. C. Elmroth, J. Chem. Soc., Dalton Trans., 1997, 1159.

16 J. Berglund and L. I. Elding, Inorg. Chem., 1995, 34, 513.

17 G. Nardin, L. Randaccio, G. Annibale, G. Natile and B. Pitteri, J. Chem. Soc., Dalton Trans., 1980, 220.

18 L. Cao, M. C. Jennings and R. J. Puddephatt, Inorg. Chem., 2007, 46, 1361.

19 L. S. Hollis and S. J. Lippard, J. Am. Chem. Soc., 1983, 105, 4293.

$20 S A D A B S$, Bruker AXS, Inc., Madison WI, U.S.A., 2009.

21 G. M. Sheldrick, Acta Crystallogr., Sect. A: Fundam. Crystallogr., 2008, 64, 112-122.

22 H. D. Flack, Acta Crystallogr., Sect. A: Fundam. Crystallogr., 1983, 39, 876-881.

23 G. Annibale, L. Canovese, L. Cattalini and G. Natile, J. Chem. Soc. Dalton Trans., 1980, 1017.

24 G. Zhao and N. D. Chasteen, Anal. Biochem., 2006, 349, 262.

25 W. Robb, Inorg. Chem., 1967, 6, 382.

26 F. Moreau, G. C. Bond and A. O. Taylor, J. Catal., 2005, 231, 105.

27 N. P. Finkelstein and R. D. Hancock, Gold Bull., 1974, 7, 72.

28 S. Ivanova, C. Petit and V. Pitchon, Appl. Catal., A, 2004, 267, 191.

29 K. Pacławski and K. Fitzner, Metall. Mater. Trans. B, 2004, 35, 1071.

30 J. A. Harrison and J. Thompson, J. Electroanal. Chem., Interfacial Electrochem., 1975, 59, 273. 
31 C. H. Gammons, Y. Yu and A. E. Williams-Jones, Geochim. Cosmochim. Acta, 1997, 61, 1971.

32 S. L. Best, Z. Guo, M. I. Djuran and P. J. Sadler, Metal-Based Drugs, 1999, 6, 261.

33 D. L. Fant and C. F. Weick, Inorg. Chem., 1973, 12, 1864.

34 W. H. Baddley, F. Basolo, H. B. Gray, C. Nölting and A. J. Poë, Inorg. Chem., 1963, 2, 921.

35 B. Pitteri, G. Marangoni, F. Visentin, T. Bobbo, V. Bertolasi and P. Gilli, J. Chem. Soc., Dalton Trans., 1999, 677.

36 J. Herszage and M. D. S. Afonso, Environ. Sci. Technol., 2003, 37, 3332.

37 S. S. Seo, X. Wang and D. Murray, Ionics, 2009, 15, 67.

38 L. Aldous, D. S. Silvester, C. Villagrán, W. R. Pitner, R. G. Compton, M. C. Lagunas and C. Hardacre, New J. Chem., 2006, 30, 1576.

39 M. Bortoluzzi, E. De Faveri, S. Daniele and B. Pitteri, Eur. J. Inorg. Chem., 2006, 3393.

40 L. Aldous, D. S. Silvester, W. R. Pitner, R. G. Compton, M. C. Lagunas and C. Hardacre, J. Phys. Chem. C, 2007, 111, 8496.

41 S. Roy, T. L. Groy and A. K. Jones, Dalton Trans., 2013, 42, 3843.

42 G. Annibale, M. Brandolisio, Ž. Bugarčić and L. Cattalini, Transition Met. Chem., 1998, 23, 715.

43 D. W. Fink and W. E. Ohnesorge, J. Phys. Chem., 1970, 74, 72 .
44 C. Bazzicalupi, A. Bencini, A. Bianchi, A. Danesi, E. Faggi, C. Giorgi, S. Santarelli and B. Valtancoli, Coord. Chem. Rev., 2008, 252, 1052.

45 K. Nakamoto, J. Phys. Chem., 1960, 64, 1420.

46 M. Zhou, J. Ding, L. P. Guo and Q. K. Shang, Anal. Chem., 2007, 79, 5328.

47 G. Hager and A. G. Brolo, J. Electroanal. Chem., 2009, 625, 109.

48 H. Wefers and H. Sies, Eur. J. Biochem., 1983, 137, 29.

49 F. Q. Schafer and G. R. Buettner, Free Radicals Biol. Med., 2001, 30, 1191.

50 V. Volarević, M. Milovanović, A. Djeković, B. Petrović, N. Arsenijević and Ž. D. Bugarčić, J. BUON, 2010, 15, 768.

51 M. Arsenijević, M. Milovanović, V. Volarević, A. Djeković, T. Kanjevac, N. Arsenijević, S. Đukić and Ž. D. Bugarčić, Med. Chem., 2012, 8, 2.

52 A. Djeković, B. Petrović, Ž. D. Bugarčić, R. Puchta and R. van Eldik, Dalton Trans., 2012, 41, 3633.

53 R. W. Y. Sun, D. L. Ma, E. L. M. Wong and C. M. Che, Dalton Trans., 2007, 4884.

54 L. Messori, F. Abbate, G. Marcon, P. Orioli, M. Fontani, E. Mini, T. Mazzei, S. Carotti, T. O'Connell and P. Zanello, J. Med. Chem., 2000, 43, 3541.

55 P. Shi, Q. Jiang, Y. Zhao, Y. Zhang, J. Lin, L. Lin, J. Ding and Z. Guo, J. Biol. Inorg. Chem., 2006, 11, 745.

56 N. H. Jang, Bull. Korean Chem. Soc., 2002, 23, 1790. 